\title{
Insect assemblages attacking seeds and fruits in a rainforest in Thailand
}

Article

Accepted Version

Basset, Y., Ctvrtecka, R., Dahl, C., Miller, S. E., Quicke, D. L. J., Segar, S. T., Barrios, H., Beaver, R. A., Brown, J. W., Bunyavejchewin, S., Gripenberg, S., Knizek, M., Kognoo, P., Lewis, O. T., Pongpattananurak, N., Pramul, P., Sakchoowong, W. and Schutze, M. (2019) Insect assemblages attacking seeds and fruits in a rainforest in Thailand. Entomological Science, 22 (2). pp. 137-150. ISSN 1479-8298 doi: https://doi.org/10.1111/ens.12346 Available at https://centaur.reading.ac.uk/81220/

It is advisable to refer to the publisher's version if you intend to cite from the work. See Guidance on citing.

To link to this article DOI: http://dx.doi.org/10.1111/ens.12346

Publisher: Wiley

All outputs in CentAUR are protected by Intellectual Property Rights law, including copyright law. Copyright and IPR is retained by the creators or other copyright holders. Terms and conditions for use of this material are defined in the End User Agreement. 


\section{CentAUR}

Central Archive at the University of Reading

Reading's research outputs online 
1 Insect assemblages attacking seeds and fruits in a rainforest in Thailand

4 Yves BASSET ${ }^{1,2,3,4}$, Richard CTVRTECKA ${ }^{2,3}$, Chris DAHL $^{2,3}$, Scott E. MILLER ${ }^{5}$, Donald

5 L. J. QUICKE ${ }^{6}$, Simon T. SEGAR ${ }^{2,3}$, Héctor BARRIOS ${ }^{4}$, Roger A. BEAVER ${ }^{7}$, John W.

6 BROWN $^{5}$, Sarayudh BUNYAVEJCHEWIN ${ }^{8}$, Sofia GRIPENBERG ${ }^{9}$, Miloš KNÍŽEK ${ }^{10}$,

7 Pitoon KONGNOO $^{11}$, Owen T. LEWIS ${ }^{9}$, Nantachai PONGPATTANANURAK ${ }^{12}$, Pairot

8 PRAMUAL ${ }^{13}$, Watana SAKCHOOWONG ${ }^{14} \&$ Mark SCHUTZE $^{15}$

9

10

$11{ }^{1}$ Smithsonian Tropical Research Institute, Apartado 0843-03092, Balboa, Ancon, Panamá.

$12{ }^{2}$ Faculty of Science, University of South Bohemia, 37005 Ceske Budejovice, Czech

13 Republic.

$14{ }^{3}$ Biology Centre of the Czech Academy of Sciences, Institute of Entomology, 37005 Ceske

15 Budejovice, Czech Republic.

$16{ }^{4}$ Maestria de Entomologia, Universidad de Panamá, 080814 Panama City, Republic of 
17 Panama.

$18{ }^{5}$ National Museum of Natural History, Smithsonian Institution, Box 37012, Washington,

19 DC 20013-7012, USA.

$20{ }^{6}$ Integrative Ecology Laboratory, Department of Biology, Faculty of Science,

21 Chulalongkorn University, Phayathai Road, Pathumwan, BKK 10330, Thailand.

${ }^{7} 161 / 2$ Mu 5, Soi Wat Pranon, T. Donkaew, A. Maerim, Chiangmai 50180, Thailand.

$23{ }^{8}$ Research Office, Department of National Parks, Wildlife and Plant Conservation,

24 Bangkok 10900 Thailand.

$25{ }^{9}$ Department of Zoology, University of Oxford, Oxford OX1 3PS, U.K.

$26{ }^{10}$ Forestry and Game Management Research Institute, Strnady 136, CZ - 25202 Jíloviště,

27 Czech Republic.

${ }^{11}$ Key Laboratory of Tropical Forest Ecology, Xishuangbanna Tropical Botanical Garden,

29 Chinese Academy of Sciences, Mengla, Yunnan 666303, China. 
31 Wan Rd, Lat Yao Chatuchak, Bangkok 10900, Thailand.

$32{ }^{13}$ Department of Biology, Faculty of Science, Mahasarakham University, Kantharawichai

33 District, Maha Sarakham 44150, Thailand.

$34{ }^{14}$ Forest Entomology Group, Department of National Parks, Wildlife and Plant

35 Conservation, Praholyothin Road, Chatujak, Bangkok 10900. Thailand.

$36{ }^{15}$ School of Earth, Environmental \& Biological Sciences, Queensland University of

37 Technology, GPO Box 2434, Brisbane, QLD 4001, Australia.

40 Correspondence: Yves Basset, Smithsonian Tropical Research Institute, Apartado

41 0843-03092, Balboa, Ancon, Panamá. E-mail: bassety@ si.edu

42

43 


\section{Abstract}

45

Insect seed predators are important agents of mortality for tropical trees, but little is known about the impact of these herbivores in rainforests. During three years at Khao Chong (KHC) in southern Thailand we reared 17,555 insects from $343.2 \mathrm{~kg}$ or 39,252 seeds/fruits representing 357 liana and tree species. A commented list of the 243 insect species identified is provided, with details about their host plants. We observed that: (1) about $43 \%$ of identified species can be considered pests. Most were seed eaters, particularly on dry fruits. (2) About 19\% of parasitoid species (all Opiinae) for which we could determine whether their primary insect host was a pest or not (all Bactrocera spp. breeding in fruits) can be considered beneficials. (3) The seeds/fruits of about $28 \%$ of the plant species in this forest were free of attack. Phyllanthaceae, Rubiaceae, and Meliaceae were attacked relatively infrequently; in contrast, Annonaceae, Fabaceae, Sapindaceae, and Myristicaceae were more heavily attacked. There was no apparent effect of plant phylogeny on rates of attack but heavily attacked tree species had larger basal area in the KHC plot than rarely attacked tree species. (4) Insects reared from fleshy fruits were more likely to exhibit relatively stable populations compared to insects reared from dry fruits, but this was not true of insects reared from dipterocarps, which appeared to have relatively stable populations throughout the study period. We tentatively conclude that insects feeding on seeds and fruits have little effect on observed levels of host abundance in this 64 forest.

67 Key words: dipterocarp, parasitoid, pest, seed predation, Tephritidae. 

INTRODUCTION Insect seed predators represent important agents of mortality for tropical rainforest trees because they often kill the plant embryo, or make the fruit unsuitable for seed dispersers (Janzen 1970; Lewis \& Gripenberg 2008). Insects feeding internally on fleshy fruits can also cause significant loss of plant fitness and economic damage, via, notably, fruit abortion (Stephenson 1981). There is an abundant literature on seed predators as pests of economic plants (e.g. Zehnder et al. 2007) or on seed- and fruit-feeding insects in temperate areas (e.g. Turgeon et al. 1994) but in comparison little is known about these in tropical rainforests where community-level studies of insects feeding on seeds (dry fruits, achenes) and fleshy fruits are extremely rare. This is because it is difficult to survey the extremely diverse range of potential host plants with adequate spatial and temporal sampling effort, particularly with regard to pre-dispersal seed predation (Ctvrtecka et al. 2014). To the best of our knowledge, there are currently only six such examples which are relatively comprehensive. (1) Janzen studies of insect seed predation in Guanacaste 
82 (targeting beetles and summarized in Janzen 1971) led to the formulation of the

83 Janzen-Connell hypothesis, explaining the coexistence of tree species in tropical forests as

84 resulting from negative density-dependence processes (Janzen 1970). (2) Nakagawa,

85 Hosaka and their colleagues have studied insect seed predation in dipterocarp forests at two locations in Malaysia (Nakagawa et al. 2003, 2005; Hosaka et al. 2009, 2011; Iku et al., 2017). (3) Copeland et al. (2009) made a broad survey of insects feeding on wild fruits in Kenya, targeting tephritids. (4) Ramírez and Traveset (2010) published a comprehensive survey of insect seed predators in different habitats in Venezuela, including discontinuous patches of forest. (5) Ctvrtecka and colleagues studied insects feeding on both seeds and

91 fruits with high sampling effort in a lowland forest of Papua New Guinea (Ctvrtecka et al. conducted a similar survey on Barro Colorado Island in Panama. The present contribution adds the first study in Thailand. We have summarized the 
96 (Basset et al. 2018) and intend to discuss interaction networks in detail elsewhere. In this

97 contribution, we attempt to answer various questions related to three general hypotheses

98 that are particularly relevant to the identity per se of the plants surveyed and insect species

99 reared. First, forests may act as reservoirs of both fruit/seed-feeding pests and their parasitoids. For example, most research on frugivorous insects from wild fruit is specifically concerned with discovering the range of reservoir hosts of fruit flies (Tephritidae), which are major pests of commercial fruit crops (Allwood et al. 1999; Copeland et al. 2009). Given that most insect herbivores in tropical rainforests are reasonably host-specific (Novotny et al. 2002), it is not immediately clear whether a relatively pristine forest may contribute significantly as a reservoir of pests of cultivated plants, or of potential parasitoids of such pests. Further, forest pests attacking the seeds of ecologically and economically important species of timber trees, such as many species of 
110 forest may also potentially act as a reservoir of pests of stored products because these

111 insects usually feed on a resource low in water (Subramanyam 1995), similar to that of

112 seed predators of dry fruits (achenes; Janzen 1980). Rainforests might also act as reservoirs

113 of beneficial insects, such as parasitoids of pest species (Aluja et al. 2014). The enemy

114 hypothesis states that predatory insects and parasitoids are more effective at controlling

115 populations of herbivores in diverse systems of vegetation than in simple ones (Russell

116 1989). For example, there is evidence that diverse wet and dry forests in Mexico and

117 Central America act as reservoirs of parasitoids attacking fruit flies in fruit orchards. This

118 mechanism contributes to the value of tropical tree conservation in Mexico (Aluja et al.

119 2014).

Second, the identity of the plants and insects involved in interactions is crucial for

121 two reasons. The identity of plants whose levels of seed/fruit attack stand out from the rest

of the local vegetation (i.e. rarely or heavily attacked) is important because it can shed light 
124 of crop protection. The identity (or absence of) of the enemies of seed eaters, such as insect

125 parasitoids, is also important because some granivores and frugivores may be relatively

126 free of enemies, perhaps suggesting effective defenses. The nasty host hypothesis proposes

127 that insect herbivores feeding on plant hosts with strong and/or distinctive chemical

128 defenses may support a reduced load of parasitoids because their tissues may be more toxic

129 to parasitoids (Gauld et al. 1992). Given the potential importance of insect seed predators

130 in tropical tree mortality (Lewis \& Gripenberg 2008), this hypothesis may have

131 consequences for the local distribution of tree species and the dynamics of their

132 populations.

Finally, seed predators are thought to be satiated by mass production of seeds,

134 which promotes escape from predation. The satiation hypothesis has been well-studied in dipterocarp forests of Malaysia (Curran \& Webb 2000). The whereabouts of seed-predators of mast-fruiting trees, such as dipterocarps in many forests, in-between periods of masting,

137 which can be as long as several years, is crucial for these specialized insects (Hosaka et al. 
138 2011). The extent of annual fluctuations of seed predators in tropical rainforests has not

139 been well-studied, with the exception of dipterocarp seed predators, which may maintain

140 populations by prolonged dormancy and/or alternative hosts (Hosaka et al. 2011). This

141 issue could help understanding patterns of insect attack on particular plant species, and

142 their local distribution and abundance. Here again the identity of both plants and insects are

143 crucial to evaluate potential patterns.

144 The general aims of this paper are to document (as far as possible) the identity of

145 insects attacking seeds and fruits, as well as their main parasitoids, in a lowland rainforest

146 in Thailand. Our specific questions are as follows:

147

1) Does this forest represent a potential reservoir of pests for seed and fruit crops or seeds

149 of valuable timber trees, such as dipterocarps, in Thailand?

2) Does this forest represent a reservoir of parasitoids potentially able to control pests of seeds and fruits in Thailand? 
152 3) Which taxa of seed/fruit-feeding insects are relatively free of parasitoids?

153 4) Which tree species suffer unusual rates of seed/fruit attack in this forest? Are these tree

154 species particularly rare or abundant in this forest?

155 5) Which insect species maintain relatively high and stable populations during the study

156 years?

157

158 MATERIALS AND METHODS

159 Study site

160 Our study site included the 24 ha ForestGEO permanent vegetation plot

161 (https://forestgeo.si.edu/; see below) at Khao Chong (KHC; $7^{\circ} 32^{\prime} \mathrm{N}, 9^{\circ} 47^{\prime} \mathrm{E}$, altitude

$162120-330 \mathrm{~m}$ ) and the surrounding forest (i.e. an area of ca. 1,500 ha). This permanent plot is

163 located in the protected lowland seasonal evergreen forest of the Khao Ban Thad Wildlife

164 Sanctuary in Southern Thailand and is described in detail by Anderson-Teixeira et al.

165 (2014). Mean annual rainfall is $2,665 \mathrm{~mm}$ and mean daily maximum air temperature is 

$27.1^{\circ} \mathrm{C}$. KHC experiences a 2 to 3 months seasonal drought from January to March

167 (drought defined as any month receiving <100 mm of rainfall: Baltzer \& Davies 2012). In the ForestGEO plot, all trees with a diameter at breast height $(\mathrm{DBH})$ of $1 \mathrm{~cm}$ or greater have been mapped and identified to species (Anderson-Teixeira et al. 2014). There are 593 tree species, representing 285 tree genera and 82 plant families in the plot, with approximately 300 species per ha (Baltzer \& Davies 2012). The proportion of plant species with dry fruits (achenes) is $26.0 \%$ and total seed rain is 7.0 dry $\mathrm{g} \mathrm{x} \mathrm{m}^{-2} \mathrm{x} \mathrm{yr}^{-1}$ (Basset et al. 2018). Although 13 dipterocarp species grow at KHC (representing $11.8 \%$ of stems and $23 \%$ of the basal area in the ForestGEO plot; Bunyavejchewin et al. 2011), phenological studies demonstrated that the reproductive phenology of the KHC forest was more similar to tropical forests with similar rainfall seasonality in other parts of the world than it was to dipterocarp-dominated forests in ever wet regions of Southeast Asia (Kurten et al. 2017). 


\section{Survey of plants and rearing of insects}

180 Plant surveying and the rearing of insects from seeds and fruits are detailed in Basset et al.

181 (2018). Briefly, in 2013 we surveyed seeds and fruits of locally abundant tree, shrub and

liana (more rarely herb) species. During 2014 and 2015, we restricted our sampling effort

to 10 plant families, which represented the most common families at KHC. We refer to

these families as focal families and they included: Annonaceae, Arecaceae, Ebenaceae,

Euphorbiaceae, Fabaceae, Lauraceae, Meliaceae, Phyllanthaceae, Rubiaceae and

Sapindaceae. Unless specified, results are detailed for all host plant species. Seeds and

fruits collected on plants or freshly fallen (without apparent decomposition) were targeted,

thus focusing on pre-dispersal attack (i.e. on insects attacking developing or mature seeds

in the canopy of trees). Host plants were identified and their seeds/fruits assigned to the

following seed and fruit "syndromes" (hereafter seed syndromes for brevity; see Basset et 
193 A2.2, non-fleshy drupe with thin mesocarp $(<5 \mathrm{~mm})$; B1, fleshy indehiscent fruit with

194 multiple seeds; B2, non-fleshy dehiscent fruit with multiple seeds; C1, dry winged seed

195 that does not develop in capsule; and C2, multiple dry seeds (with or without wings) that

196 develop in a capsule/pod (opening across one axis). These categories were recombined in

197 some analyses as just 'fleshy fruits' (= A1.1, A1.2, B1) or just 'dry fruits' (achenes= A2.1,

198 A2.2, B2, C1, C2). Rearing sample units included clusters of conspecific seeds/fruits of similar size collected from the same trees. We targeted as many individuals as possible for each plant species, typically $>5$. These sample units were weighed (fresh weight) and stored in individual plastic pots. Pots were lined with tissue paper and covered with very fine netting for ventilation and to avoid subsequent colonization/contamination of fruits by, notably, drosophilid flies (Copeland et al. 2009). Rearing pots were stored under semi-natural conditions in covered but ventilated sheds under the forest canopy. They were checked twice weekly, and any emerging insects were collected, preserved, mounted and then 
207 identified (see below). Seeds/fruits were stored for 3 months, and then dissected to ensure

208 that there were no developing larvae inside. Seed/fruits with live larvae were reared for

209 longer, while other seeds/fruits were discarded.

211 Insect identification

212 The level of identification was unequal among insect orders owing to the availability of

213 specialists on particular insect groups. In general, beetle and moth families were identified

214 mostly to species level, whereas for Diptera and Hymenoptera only Stratiomyidae,

215 Tephritidae and Ichneumonoidea were sorted to species level. We obtained DNA

216 Cytochrome c oxidase subunit I (COI, 'DNA barcode') sequences from legs of

217 representative specimens, and we used Barcode Index Numbers (BINs) derived from insect

218 sequences to delineate species (Ratnasingham et al. 2013). Unfortunately, most of the

219 original high-quality DNA samples were spoiled in the sequencing laboratory of the

220 Smithsonian Tropical Research Institute, and in the meantime the remaining specimens 
221 had been exposed to high humidity, so we were unable to obtain DNA sequences from all

222 species. Data were deposited in the Barcode of Life projects KHCSP and KHCTE (398

223 sequences). Full specimen data for specimens sequenced (including those that failed),

224 including images and host plants, are available on BOLD (www.boldsystems.org),

225 accessible from the data set KHCFRUIT using a DOI

226 (dx.doi.org/10.5883/DS-KHCFRUIT). Morphological identification of specimens, when

227 possible, was performed by RT, SEM, JWB, DLJQ, MK, PP, MS, and by colleagues cited

228 in the Acknowledgements. For Lepidoptera, nomenclature follows Holloway (2011) and

229 Holloway et al. (2001). Insect vouchers are deposited at the Thai Department of National

230 Parks, Wildlife and Plant Conservation, Bangkok, Thailand, and the National Museum of

231 Natural History, Smithsonian Institution, Washington, D.C.

Insects reared from seeds/fruits were assigned to a guild system at the family,

233 subfamily, or in some cases at the generic or specific level (details in Basset et al. 2018).

234 Here we only consider three guilds: seed eaters (coded as SE: larva feeding mostly on seed 
235 tissue), pulp eaters (PU: larva feeding mostly on mesocarp tissue), and parasitoids (PA:

236 larva feeding on insect hosts). Members of the moth families Blastobasidae and Tineidae,

237 which are predominantly scavengers, were not included in the analyses, but when available,

238 we nevertheless provided basic information about them.

Assessing the pest status of insect species identified is not an easy task. For

240 Lepidoptera, we examined the list of species of economic importance compiled by Zhang

241 (1994). We further considered for pest species the number of citations occurring in the

242 Review of Applied Entomology (up to 1994) as an indication of the severity of the pest

243 (Zhang 1994). Additionally, we considered the host records of Kuroko and Lewvanich

244 (1993) for Thailand. For Tephritidae we followed the nomenclature and pest status as

245 indicated in Doorenweerd et al. (2018). The pest status of Scolytinae was inferred from

246 Browne (1961) and other sources indicated in Appendix S1, as for the rest of beetles.

247 Finally, we also considered the species listed as pests and beneficial insects in Thailand

248 (Hutacharern \& Tubtim 1995). 
250 Braconidae and Icheumonidae (both Ichneumonoidea) and their insect hosts; these two

251 families represented most of the parasitoids that we reared. Unlike with the host plants, our

interpretations of the hosts of the reared parasitoids only reflect 'high expectations of interactions', not documented interactions. This is because parasitized hosts were not

254 isolated and reared individually, the parasitoids instead being reared from samples including relatively high numbers of seeds and fruits. To assign putative hosts to each

256 parasitoid species, we applied three simple rules in decreasing number of importance: (1)

257 since many ichneumonoid lineages are rather conservative in host use, we followed Quicke

258 (2015) to select the most likely host order or family; (2) we then examined for each

259 parasitoid species, the co-occurrence of primary consumers in each sample from which this parasitoid species was reared; and finally (3) we considered the highest abundance of

261 putative host reared in samples in which the parasitoid species was also reared. We 


\section{Statistical analyses}

265 A main host plant/insect was defined if $80 \%$ of reared individuals originated from this host.

266 Sampling effort for a particular plant species may be assessed as either the number of

267 samples obtained, or the sum of seeds collected, or the total weight of seeds. To examine

268 which plant species were rarely attacked by insects, we considered species with a high

269 number of seeds collected but none attacked (i.e. no insect reared from the seeds), as this

270 variable is more directly relevant to the regeneration of the plant species. We considered

271 the distribution of the number of seeds free of attack for each tree species, ranked in

272 decreasing number. Host species 'rarely attacked' were defined as species belonging to the

273 first quartile of this distribution. It was more challenging to define host species 'heavily

274 attacked' and for this we considered insect load on their hosts both in term of species

275 richness and abundance. With regard to insect species richness, we considered for each

276 host species, the number of insect species reared from a main host, excluding insect 
277 singletons. With regard to insect abundance, we considered the number of insects reared

278 per seed (per unit seed), to reduce the effect of sampling effort, and calculated these values

279 for hosts relatively well sampled (for which $>75$ seeds were collected). We compared the

280 abundance in the KHC permanent plot of rarely vs. heavily attacked tree species

281 (abundance not defined for liana species) with Mann-Whitney tests for the variables

282 Number of stems (i.e. number of individuals per tree species) and Basal area (i.e. total

283 cross-sectional area of all stems in the plot measured at breast height).

Our analyses about insect inter-annual variation in abundance are limited by only

2853 years of data, but motivated by the lack of data for tropical species other than those

286 attacking dipterocarp seeds (i.e. Nakagawa et al. 2003). We used the stability index of

287 Wolda (1983) to estimate the magnitude of change in insect abundance between study

288 years (2013-2015). The index is calculated as the natural logarithm of the variance in the

natural logarithms of the abundances $(+1)$ of the individuals species. We included insect 
291 considered the average number of insects reared per seed among samples obtained each

292 year as a measure of insect abundance. We tested for differences in the average stability

293 index of species (a) of pulp vs. seed eaters, (b) reared from dipterocarps vs.

294 non-dipterocarps, and (c) reared from fleshy vs. dry fruits with Mann-Whitney tests. For (b)

295 and (c) we considered only insects reared from a main host, in order to relate unequivocally

296 insect species to either plant family or seed syndrome. Raw data (abundance per year) for

297 insect species are indicated in Appendix S1.

We evaluated the influence of host plant phylogeny on our results as follows. First,

299 we estimated the phylogenetic relationships between host species present at KHC using the

300 software package Phylomatic (Webb \& Donoghue 2005; details in Basset et al. 2018).

301 Second, we tested for phylogenetic signal for all tree species attacked, for trees rarely or heavily attacked, and for host trees from which Ichneumonoidea were reared. We calculated the D statistic for phylogenetic signal in a binary trait (Fritz \& Purvis 2010). The 
305 phylogeny. Highly clumped traits tend to have lower D values, closer to 0 . We compared

306 the scaled value of the observed D statistic to values generated under a simulated Brownian model of phylogenetic structure and one resulting from no phylogenetic structure (each with 10,000 permutations) using the $\mathrm{R}$ package 'Caper' (Orme 2013). We used a complementary significance-based approach to provide further support for these results, by between tree species. We used standardized effect sizes of MPD generated under null models of tip label randomization (999 runs) as implemented in the R package 'Picante'

313 (Kembel et al. 2010).

315 RESULTS

317 Faunal composition and occurrence of pests and beneficial insects

318 During the three-year study, we collected 1,970 samples comprising $343.2 \mathrm{~kg}$ or 39,252 seeds/fruits from 357 liana and tree species (and a few herbs) representing 66 plant families. 
320 From these samples we reared 17,555 insects $(8,851$ individuals from the 10 focal plant

321 families). There was a relatively high incidence of Alysiinae (Hymenoptera: Braconidae)

and a relatively low incidence of Bruchinae (Coleoptera: Chrysomelidae), Baridinae

S1 details the 243 species (totaling 8,949 individuals) in the guilds of seed/pulp eaters and parasitoids that we were able to identify or morphotype. About $71 \%$ of the morphospecies could be identified to genus and $28 \%$ of them to species. This material included mostly beetles, with Curculionidae (53 spp. and 5,644 individuals; including 22 spp. and 4,262 individuals of Scolytinae) and Anthribidae (8 spp. and 396 individuals) predominating.

330 Tephritidae and Stratiomyidae represented 26 and 8 species, and 814 and 464 individuals, respectively. Moths were dominated by Tortricidae (16 spp., 337 indivdiuals), Crambidae 
334 were pulp eaters (127 spp., 73.7\% of individuals), followed by seed eaters (55 spp., 22.5\%)

335 and parasitoids (62 spp., 4\%; Appendix S1). Among pulp eaters, two species of

336 Coccotrypes were the most abundant and reared from numerous hosts, whereas the most

337 abundant seed eater was an unidentified species of Aclees reared mostly from Mucuna

338 phaseoleae (Fabaceae). Note that the scolytines $C$. carpophagus, $C$. dactyliperda and $C$.

339 gedeanus may be considered as seed eaters rather than pulp eaters (Appendix S1). In

340 addition, 796 specimens of Tineidae and Blastobasidae were reared from 56 host species,

341 but the larvae of these families are more likely to be scavengers. We reared at least one

342 species of Lateantenna (Blastobasidae, L. inana (Butler, 1881)), one of Opogona

343 (Tineidae), three of Phaeoses (Tineidae), and one of Tineovertex (Tineidae).

344 Of the 69 taxa identified to species-level, 30 (43\%) may be considered pests

345 (Appendix S1). This includes two ambrosia beetles that usually do not breed in seeds. The

346 insect taxa in which the proportions of reported pest species to species identified were

347 highest included: Nanophyidae (100\%), Crambidae (67\%), Tortricidae (55\%), Scolytinae 
348 (36\%), and Tephritidae (26\%). The origin of these pest species is summarized in Fig. 1.

349 Most pests were seed eaters, and were reared mostly from Dipterocarpaceae and from hosts

350 with seed syndromes C1 (dry winged seed) and A1.2 (fleshy drupe with thin mesocarp).

351 Most pest species and individuals were reared from dry fruits as opposed to fleshy fruits

352 (Fig. 1). Only one pest of stored products, Pyralis pictalis, was reared from the seeds and mostly belonging to the Curculionidae, Nanophyidae and Tortricidae. The most abundant

fruits collected in the Khao Chong forest.

We obtained 57 samples from seven of 13 dipterocarp species growing at KHC, totaling 1,240 seeds $(10.3 \mathrm{~kg} ; 3.1 \%$ of total seeds reared), which yielded 425 insects (14 samples lacked insects). Out of these, we obtained 236 weevils and moths whose individual larvae likely feed on and kill a single seed (Hosaka et al. 2009). This suggests that about $19 \%$ of dipterocarp seeds were lost to weevils and moths. Insects reared from dipterocarp seeds included at least 26 species of seed and pulp eaters (Appendix S2), species were an unidentified species of Alcidodes (Curculionidae) reared from Parashorea 
362 stellata, and Andrioplecta shoreae reared from four dipterocarp hosts. In comparison

363 Nakagawa et al. (2003) reared 1,419 insects representing 51 species from 20,215 seeds of

36424 dipterocarp species in Sarawak. Only four species were in common between their study

365 and ours (Appendix S2). In Pasoh, Malaysia, Hosaka et al. (2009) recorded at least 32

366 insect species from two consecutive mast-fruiting events of 15 species of dipterocarps

367 (3,779 insects reared from 27,483 seeds). Senthilkumar et al. (2009) studied seed predation

368 in Dipterocarpus retusa in Assam, India, and recorded nine species of seed predators. In

369 Thailand, at least 12 species of seed predators have been recorded from dipterocarps

370 (Hutacharern \& Tubtim 1995; DNP 2018). Because of incomplete identifications, different

371 taxonomists studying the insect material and inconsistent use of DNA barcoding, it is

372 difficult to compare the lists of taxa provided by these dipterocarp studies. Nonetheless, they suggest a relatively low overlap with the fauna feeding on dipterocarp seeds at KHC.

The densities of reared insect individuals per dipterocarp seed appears to be higher at Khao 
376 insect per seed; Nakagawa et al., 2003) or Pasoh (0.14 insect per seed; Hosaka et al. 2009),

377 during periods of mast fruiting. One species of Blastobasidae and two species of Tineidae

378 were reared from Dipterocarpaceae at KHC.

verify whether the host was considered a pest of fruits or seeds, 5 species $(18.5 \%)$ could be pests (Tephritidae) breeding in the fruits of many host plant species. In addition, the larvae of Hermetia illucens recycle manure, so this species can be also considered beneficial (Appendix S1).

\section{Levels of parasitism of insects attacking seeds and fruits}

Our data allowed us to present only crude estimates of the level of parasitism due to 
parasitism was not notably different between pulp and seed eaters (Fisher exact test, $\mathrm{p}=$

391 0.483). Tephritidae was the most commonly attacked family by Braconidae, followed by

392 Curculionidae (not including Scolytinae). Bactrocera irvingiae and Andrioplecta shoreae,

reared from several host plant species, appeared to be the species most commonly

parasitized by braconids. Insect taxa that appeared to be infrequently parasitized (Table 1:

than braconids. For example, Coccotrypes spp. (Scolytinae) are known to be attacked by

the braconid genera Spathius, Bracon and Diospilus (Quicke, 2015). These genera were infrequently reared at Khao Chong and obtained from other putative hosts. We also note that there was no obvious correlation between the number of species of parasitoids and prey reared from particular plant families (only main hosts considered: Spearman rank correlation, $\mathrm{r}_{\mathrm{s}}=0.112, \mathrm{p}>0.25, \mathrm{n}=31$ plant families). Finally, most species of parasitoids 
406 Of 357 plant species surveyed, seeds/fruits of 101 were free of attack (28.3\%). The first

quartile of the distribution of these species represented $71 \%$ of the total number of seeds not attacked. Antidesma neurocarpum (Phyllanthaceae) was the most avoided plant species, with 344 seeds not attacked (Fig. 2). Other tree species rarely attacked (first quartile of the

410 distribution in Fig. 2) included 11 Rubiaceae, 9 Annonaceae, 9 Arecaceae, 7 Meliaceae,

411 and 6 Euphorbiaceae, Fabaceae and Phyllanthaceae each. Plant families with a high

412 proportion of seeds not attacked (> 15\%) included Apocynaceae, Clusiaceae, Meliaceae,

413 Anacardiaceae, Rubiaceae, Celastraceae, Phyllanthaceae, Sapotaceae (Fig. 2). Of those,

414 Phyllanthaceae, Rubiaceae and Meliaceae were species-rich and collected with a high

415 sampling effort, and hence, may be considered as families relatively infrequently attacked

416 by insects. Seed syndrome B2 (non-fleshy) also had a relatively high proportion of seeds

417 free of attack (Fig. 2). 
419 species and 16 plant families. Only Parashorea stellata (Dipterocarpaceae) and

420 Lepisanthes rubinigosa (Sapindaceae) supported more than two insect species.

421 Dipterocarpaceae, Annonaceae and Fabaceae had a relatively high load of insect species, as well as seed syndromes B1, A1.2 and C1, a mixture of dry and fleshy fruits (Fig. 3a). insect reared were obtained from Mezzettia parviflora (Annonaceae). Overall densities of insects were also relatively high on Meliaceae and Anacardiaceae (Fig. 3c). On average the highest densities of insect reared per seed and plant species were obtained from hosts with

428 Syndrome C2 (multiple dry seeds). There was no significant difference between the number of stems in the plot of tree species rarely and heavily attacked (Mann-Whitney $\mathrm{U}=$ 
$432 \mathrm{~m}^{-2} \pm 1.145$ and $1.28 \mathrm{~m}^{-2} \pm 0.439$, respectively).

$434 \quad$ Insect fluctuation during study years

435 Overall the highest densities per unit seed over the three-year study were attained by

436 several species of Scolytinae (Appendix S1). There was no significant difference between

437 the average stability index of pulp-eating species and that of seed-eating species

438 (Mann-Whitney test, $\mathrm{U}=1481.5, \mathrm{p}=0.927$ ). However, the average stability index of

439 species reared from dipterocarp hosts was significantly smaller (more stable) than that of

440 species reared from non-dipterocarp hosts $(U=710.0, p=0.027$; Fig. 4a). Further, the

441 average stability index of species reared from fleshy fruits was significantly smaller (more

442 stable) than that of species reared from dry fruits $(U=313.0, p=0.010$; Fig. 4b).

444 Host plant phylogenetic signals

445 Fig. 5 provides a visual interpretation of how all/rarely/heavily attacked plant species, and 
446 from which Ichneumonoidea were reared, clustered across the whole plant phylogeny at

447 KHC. The three first categories showed a limited phylogenetic signal with the D statistic

448 relatively high (all plant species attacked: $D=0.862, p(D>0)=0.0001, p(D<1)=0.0001$;

449 species rarely attacked: $D=0.781, p(D>0)=0.005, p(D<1)=0.0023$; species heavily attacked:

$450 \mathrm{D}=0.855, \mathrm{p}(\mathrm{D}>0)=0.025, \mathrm{p}(\mathrm{D}<1)=0.0001)$. For plant species hosting Ichneumonoidea,

451 there was clearly no phylogenetic signal $(D=0.994, p(D>0)=0.418, p(D<1)=0.0001)$.

452 Significance tests of phylogenetic signal according to MPD indicated that all categories

453 were not clumped across plant phylogeny (all species: MPD observed $=358.9$, MPD

454 random mean $=342.5, \mathrm{p}=0.92 ;$ species rarely attacked: $\mathrm{MPD}$ observed $=305.3, \mathrm{MPD}$

455 random mean $=328.1, \mathrm{p}=0.23$; species heavily attacked: MPD observed $=364.8$, MPD

456 random mean $=329.6, \mathrm{p}=0.88$; species hosting Icheumonoidea: MPD observed $=355.9$,

$457 \quad$ MPD random mean $=330.3, \mathrm{p}=0.78)$.

458

459 DISCUSSION 
461 Insect assemblages feeding on seeds and fruits in tropical rainforests are challenging to

462 study, primarily because of low rates of attack, high plant diversity, and the high sampling

effort required to rear sufficient numbers of insect specimens to provide meaningful

statistics (Ctvrtecka et al. 2014). Further, the taxonomic knowledge of insects reared from

native seeds and fruits of tropical countries is often limited (Nakagawa et al. 2003; Miller

et al. 2014). Regarding the questions asked in this study, we observed that (1) about $43 \%$ of

species identified could be considered pests. Most were seed eaters, particularly on dry

fruits (but only a single pest of stored products was recorded), belonging to Nanophyidae,

469 Tortricidae, Crambidae, Scolytinae and Tephritidae. (2) About 19\% of parasitoid species

470 for which we could assess whether the main insect host is a pest could be considered

471 beneficial. All these species were Opiinae with Bactrocera pests breeding in fruits as main

hosts. (3) Overall about $8 \%$ of insect species reared from seeds/fruits were parasitized by 
475 seeds/fruits of Phyllanthaceae, Rubiaceae and Meliaceae were attacked relatively

476 infrequently by insects. In contrast, fruits and seeds of species of Annonaceae, Fabaceae,

477 Sapindaceae and Myristicaceae were more likely to be heavily attacked, with multiple dry

478 seeds (Syndrome C2) often well attacked. There was no apparent effect of plant phylogeny

479 on rates of attack but heavily attacked tree species had larger basal area in the KHC plot

480 than rarely attacked tree species. (5) The highest densities per unit seed over the three study

481 years were attained by several species of Scolytinae, as these beetles may produce large

482 brood inside fruits. Insects reared from fleshy fruits were more likely to exhibit relatively

483 stable populations compared to insects reared from dry fruits, except for insects reared

484 from dipterocarps, which appeared to have relatively stable populations during the study

485 years at KHC.

The proportion of pest species recorded in our study is probably inflated because

487 in the tropics insect pests are far better known than native forest insects, especially those 
categories of pests: (1) various beetles species breeding in the dry seeds of dipterocarps that

491 Tephritidae breeding in fleshy fruits. The former species could be of concern because modest dipterocarp plantations have been established in Thailand since the 1980s (Weinland 1998). However, densities of the most common pest feeding on dipterocarps, Alcidodes sp. 15, were rather low, reaching 0.16 insect per seed on average during the three-year study. Bactrocera irvingiae was the most commonly reared tephritid from fleshy fruits, but this species is not considered a pest. Dacus longicornis, a pest of Cucurbitaceae, reached densities of 0.44 flies per fruit on our focal hosts, but was not very abundant when all plant species surveyed were considered. We conclude that during our study years the

499 KHC forest did not support insect pests in densities that may cause concern to timber species (dipterocarps) or fruit crops. Less than $20 \%$ of parasitoid species appeared to have insect pests as hosts. Since we have little evidence that the KHC forest acts as a reservoir of 
beneficial insect species. A better test of this issue would be to compare parasitoid and seed

504 insect assemblages in commercial crops contiguous with natural forests, such as in Mexico

505 (Aluja et al. 2014). However, in Thailand such situations are rare, with habitats contiguous to natural forests represented primarily by buffalo fields, maize plantations, or holiday resorts (DJ Quicke, pers. obs.).

A more interesting question related to parasitoids is whether some seed insects may be relatively free of ichneumonoid parasitoids. In Costa Rica, Janzen (1980) observed that Bruchinae seed predators are rarely attacked by parasitoids. At KHC Bruchinae are replaced by Anthribidae and Curculionidae (Basset et al. 2018), whose species frequently were attacked (except for Scolytinae, Table 1). Further, many of the Tephritidae species were attacked by braconids. We reared about $50 \%$ fewer individuals of Stratiomyidae

514 (Appendix S1) but did not record any braconid attacks on these flies. There are very few

515 Ichneumonoidea parasitoids of Stratiomyidae (Quicke 2015), which are attacked only as 
517 there was no obvious correlation (negative or positive) between the number of prey and

518 parasitoids reared from particular plant families, and that there was no phylogenetic signal

519 relating host plant species from which Ichneumonoidea were reared. Although these

520 represent weak tests of the nasty host hypothesis (Gauld et al. 1992), these observations do

521 not appear to support it (and see Quicke 2012 for other considerations). Our rearing scheme,

522 albeit imperfect to obtain reliable data about the identity of parasitoid hosts and level of

523 parasitism, nevertheless suggests that the action of parasitoids at KHC may be too

524 infrequent to induce strong differences in seed/fruit crops, with possible consequences on

525 local tree abundance.

526 There are certainly different reasons for seeds of particular plant species to be

527 attacked less frequently by insects. First, plant chemistry may be an important determinant;

528 because seeds represent the most valuable part of the plant, they are usually well protected

529 (Janzen 1969; Ramírez \& Traveset 2010). At present we lack data for most KHC plant 
531 such a discussion). Our phylogenetic tests indicated only limited phylogenetic signal for

532 the categories of plant species attacked by seed and pulp eaters, as well as for plant species

533 rarely of heavily attacked. This suggests that insects overall may not be very selective

534 regarding attacking or avoiding particular clades of plant species, even if they may be

535 reasonably host specific. Second, sample size is certainly important (Ctvrtecka et al. 2014),

536 but among our focal plant families, we could nevertheless crudely assign species to the

537 categories rarely and heavily attacked. The next important variable is probably local host

538 abundance. We found that host species heavily attacked have on average a higher basal area

539 (but not number of stems) in the KHC plot than rarely attacked host species. This suggests

540 that seed and pulp eaters are influenced primarily by seed/fruit production, which is

541 probably more dependent on basal area than on number of stems. It seems less likely that

542 seed and pulp eaters are directly limiting the local abundance of heavily attacked tree

543 species. 
545 (Kurten et al. 2017), and insect densities in dipterocarp seeds during the study years were

546 higher than in Malaysian dipterocarp forests experiencing mast fruiting (Nakagawa et al.

547 2003; Hosaka et al. 2009), support the hypothesis of satiation of seed predators by mast

548 fruiting (Curran \& Webb 2000). However, it is not clear why insects reared from

549 dipterocarp seeds at KHC should have more stable populations than insects reared from

550 non-dipterocarp hosts. This may be related to easy host-switching and alternative hosts for

551 insects feeding on dipterocarp seeds (Nakagawa et al. 2003). The low faunal turnover

552 between dipterocarp insects at Khao Chong and in Malaysia is also of interest, suggesting

553 that different insect assemblages may be well adapted to either mast-fruiting events or the

554 lack of these events. We also strongly suspect that low host specificity in insects breeding

555 in fleshy fruits may explain the more stable populations of these species as opposed to

556 those breeding in dry fruits. This issue will be explored elsewhere with more adequate data. 
559 Insect densities were low, as was the number of confirmed insect pests, and heavily

560 attacked tree species were not notably less abundant than other species. This situation

appears similar to that described for a lowland rainforest in Papua New Guinea (Ctvrtecka

et al. 2014; Sam et al. 2017). This could be a consequence of the high plant diversity at

564 fruits (Basset et al. 2018). It is obvious that more surveys of insects feeding on seeds and

fruits are required at different rainforest locations to discuss adequately this issue.

\section{ACKNOWLEDGMENTS}

569 We thank the Khao Chong Botanical Garden (Thailand) for logistical support. Collecting

permits were obtained from the National Research Council of Thailand. Montarika

Panmeng and Sutipun Putnaul collected most of the insect material, which was identified

as indicated in the main text and with the further help of Jeremy Holloway, Steve 
574 supported by the Czech Science Foundation (16-20825S). Grants from the Smithsonian

575 Institution Barcoding Opportunity FY013 and FY014 (to YB) and in-kind help from the

576 Canadian Centre for DNA Barcoding and Southern China DNA Barcoding Center allowed

577 to sequence insect specimens. YB and HB are members of the Sistema Nacional de

578 Investigación, SENACYT, Panama. SG holds a Royal Society University Research

579 Fellowship. MK was partly supported by the Ministry of Agriculture of the Czech Republic

580 (Resolution RO0117; 6779/2017-MZE-14151). DLJQ was supported by the

581 Ratchadaphiseksomphot Fund, Chulalongkorn University.

REFERENCES

585 
Allwood AJ, Chinajariyawong A, Kritsaneepaiboon S, Drew RAI, Hamacek EL, Vijaysegaran S (1999) Host plant records for fruit flies (Diptera: Tephritidae) in southeast Asia. The Raffles Bulletin of Zoology Supplement no. 7, 1-92. management through tropical tree conservation. Biodiversity and Conservation 23, $831-853$. tropical tree species' distributions. Ecology and Evolution 2, 2682-2694. 

too rare to cause Janzen-Connell effects in New Guinea lowland rainforest. Journal of Tropical Ecology 30, 521-35. 

Plant Conservation Department. Available from URL: checklist of the 932 fruit fly species in the tribe Dacini (Diptera, Tephritidae). ZooKeys 730, 17-54. at risk in the world's mammals. Proceedings of the Royal Society, Series B, 

and the anomalous diversity of tropical parasitoids: the "nasty" host hypothesis. Oikos 65, 353-357. Ecology 106, 87-100. moths and butterflies. Brill, Leiden. xii +456 pp. pre-dispersal seed predatory insects on eleven Shorea (Dipterocarpaceae) species. 

insect seed predators and intensity of seed predation on Shorea (Dipterocarpaceae) in two consecutive masting events in Peninsular Malaysia. Journal of Tropical Ecology 27, 651-655. Environmental Policy and Planning, Bangkok, Thailand. MY et al. (2017) Increased seed predation in the second fruiting event during an Janzen DH (1969) Seed-eaters versus seed size, number, toxicity and dispersal. exceptionally long period of community-level masting in Borneo. Ecological Research 32, 537-545. 

Janzen DH (1971) Seed predation by animals. Annual Review of Ecology and Systematics 2, 465-492. forest. The Journal of Ecology 68, 929-952. Survey Bulletin 33, 141-174. 26, 1463-1464. 

Ecology 106, 126-136. microlepidoptera reared from native fruit in Kenya. Proceedings of the (2003) Resource use of insect seed predators during general flowering and 

predation by insects vs. vertebrates in six dipterocarp species in Sarawak, Malaysia. Biotropica 37, 389-396. 841-844. evolution in R. R package version 5,1-36. conclusions about latitudinal trends in species richness, body size and biology. PLoS One 7, e32101. 

taxonomic groups. Perspectives in Plant Ecology, Evolution and Systematics 12, 193-209. sugarcane soldier fly, Inopus rubriceps (Dip.: Stratiomyidae). Agriculture, Ecosystems \& Environment 19, 343-363. Russell EP (1989) Enemies hypothesis: a review of the effect of vegetational diversity on predatory insects and parasitoids. Environmental Entomology 18, 590-599. 

Low host specificity and abundance of frugivorous Lepidoptera in the lowland rain forests of Papua New Guinea. PloS One 12, e0171843. Forest Science 21, 8-12. functions. Annual Review of Ecology and Systematics 12, 253-279. Subramanyam B (ed) (1995) Integrated Management of Insects in Stored Products. CRC Press, Boca Raton. Turgeon JJ, Roques A, Groot PD (1994) Insect fauna of coniferous seed cones: 
Webb CO, Donoghue MJ (2005) Phylomatic: Tree assembly for applied phylogenetics.

Molecular Ecology Notes 5, 181-183. 
734 section at the end of the article.

Appendix S1. Details of insects reared from seeds and fruits and Khao Chong.

Appendix S2. Seed and pulp eaters reared from Dipterocarpaceae at Khao Chong.

739

740

741 
$742 \quad$ Figure legends

745 Figure 1 Source of pest species recorded at Khao Chong, detailed for species and

746 individuals and by (a) insect families, (b) insect guilds, (c) main host family and (d) main

747 host seed syndromes. Curculionoidea do not include Scolytinae, which are indicated

748 separately.

750 Figure 2 Plant species free of seed attack. (a) Inset: full distribution of the number of seeds

751 free of attack for each species not attacked; main figure: first quartile of the distribution

752 with name of species detailed and plant families abbreviated and colored similarly. (b)

753 Proportion of seeds free of attack (black) detailed by plant family (when no. of plant

754 species surveyed $\geq 3$ ). (c) Same, detailed by seed syndrome. Abbreviations of plant

755 families: An=Anacardiaceae; Ao=Annonaceae; Ap=Apocynaceae; Ar=Arecaceae;

$756 \mathrm{Cl}=\mathrm{Clusiaceae} ; \quad \mathrm{Er}=$ Erythroxylaceae; $\quad \mathrm{Eu}=$ Euphorbiaceae; $\quad \mathrm{Ge}=\mathrm{Gentianaceae}$ 
757 La=Lauraceae; Lo=Loganiaceae; Ly=Lythraceae; Me=Meliaceae; Mo=Moraceae;

$758 \mathrm{Ph}=$ Phyllanthaceae; Po=Poaceae; Ru=Rubiaceae; Un=Unknown.

760 Figure 3 Heavily attacked plant species. (a) Number of insect species (white = pulp eaters,

761 black $=$ seed eaters) reared from main hosts (as defined in methods), detailed by plant

762 families. Inset: same presentation, detailed by seed syndrome. (b) Number of insects reared

763 per seed for the 25 most attacked plant species. Black $=$ seed eaters, white or different

764 colour $=$ pulp eaters $($ same colour denotes same plant family). (c) Average number of

765 insects reared per seed and plant species, detailed by plant family (white $=$ pulp eaters,

766 black $=$ seed eaters). (d) Same presentation, detailed by seed syndrome. Abbreviations of

767 families for (b): An=Anacardiaceae; Ao=Annonaceae; Ar=Arecaceae;

768 Ch=Chrysobalanaceae; Di=Dilleniaceae; Di=Dipterocarpaceae; Eb=Ebenaceae;

769 Eu=Euphorbiaceae; Fa=Fabaceae; La=Lauraceae; Me=Meliaceae; Mo=Moraceae;

770 My=Myristicaceae; $\mathrm{Ru}=$ Rubiaceae; $\mathrm{Sa}=$ Sapindaceae. 
772 Figure 4 Insect species ranked by their stability index. (a) Species reared from

773 non-dipterocarp hosts (grey bars) vs. species reared from dipterocarp hosts (black bars). (b)

774 Species reared from fleshy fruits (grey bars) vs. dry fruits (black bars).

775

776 Figure 5 Maximum clade credibility consensus trees depicting the phylogenetic

777 relationships between 622 host plant species, with for each consensus tree, taxa marked in

778 red indicate (a) all species attacked, (b) species rarely attacked, (c) species heavily attacked

779 and (d) species from which Ichneumonoidea were reared. 

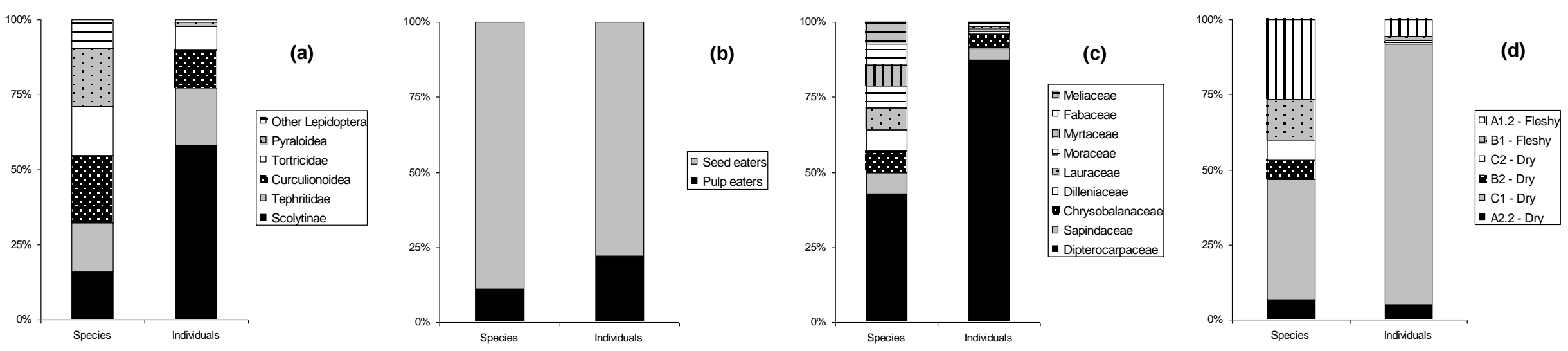

......./Users/zool0827/AppData/Local/Temp/FigsKHCSeedInsects.ppt - 256,1,Slide 1

Figure 1 Source of pest species recorded at Khao Chong, detailed for species and individuals and by (a) insect families, (b) insect guilds, 

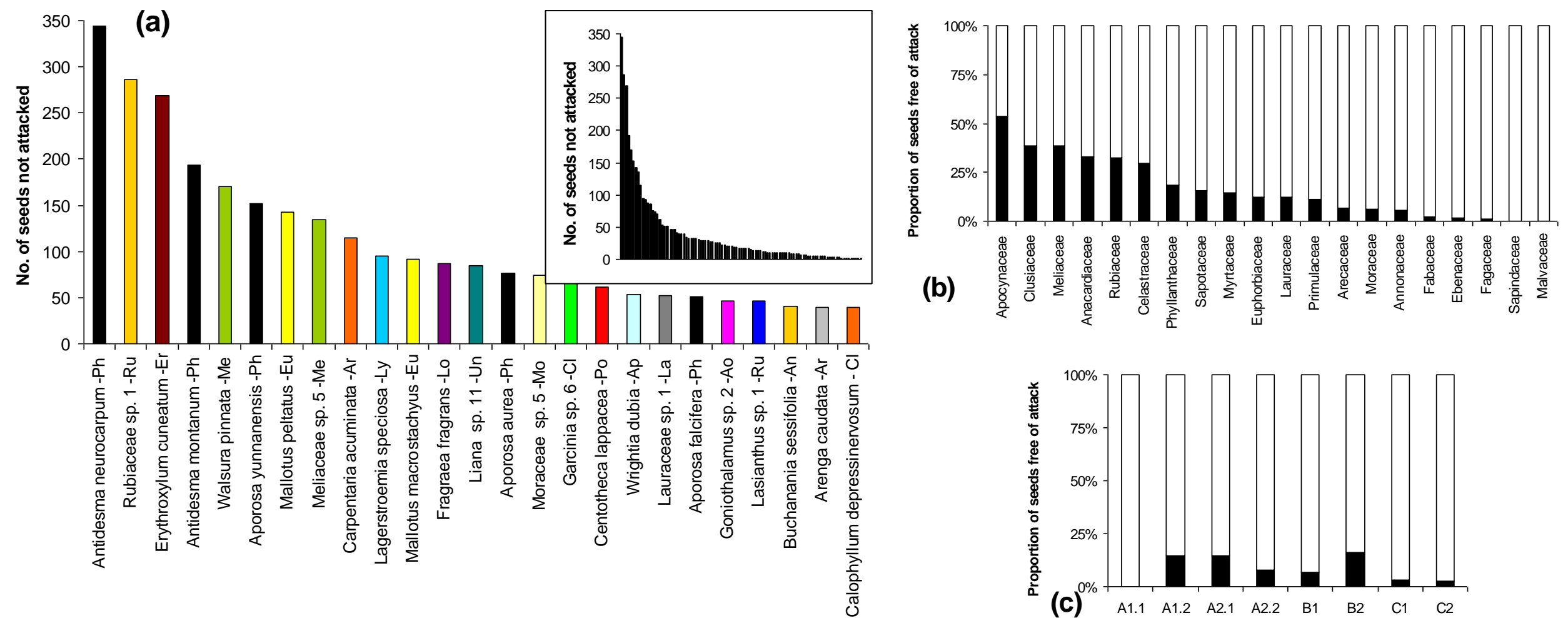

(b)

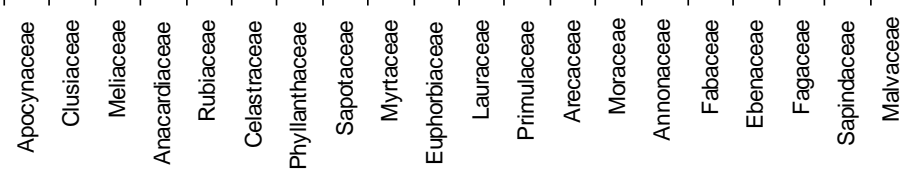

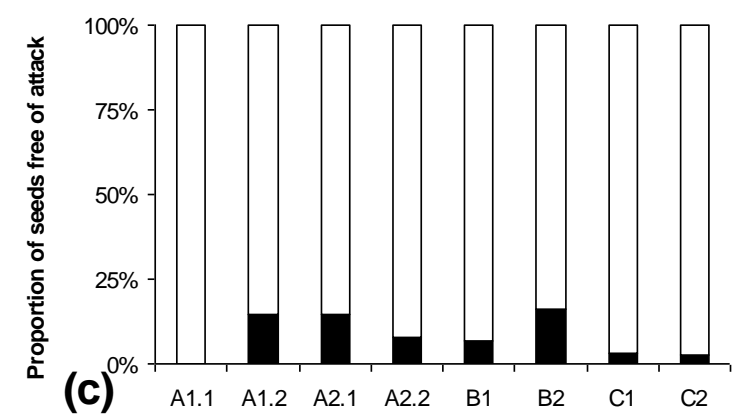

788

789

790

Figure 2 Plant species free of seed attack. (a) Inset: full distribution of the number of seeds free of attack for each species not attacked; main figure: first quartile of the distribution with name of species detailed and plant families abbreviated and colored similarly. (b) 
Proportion of seeds free of attack (black) detailed by plant family (when no. of plant species surveyed $\geq 3$ ). (c) Same, detailed by seed

794 syndrome. Abbreviations of plant families: $\mathrm{An}=\mathrm{Anacardiaceae} ; \mathrm{Ao}=\mathrm{Annonaceae} ; \mathrm{Ap}=\mathrm{Apocynaceae} ; \mathrm{Ar}=\mathrm{Arecaceae} ; \mathrm{Cl}=\mathrm{Clusiaceae}$; 


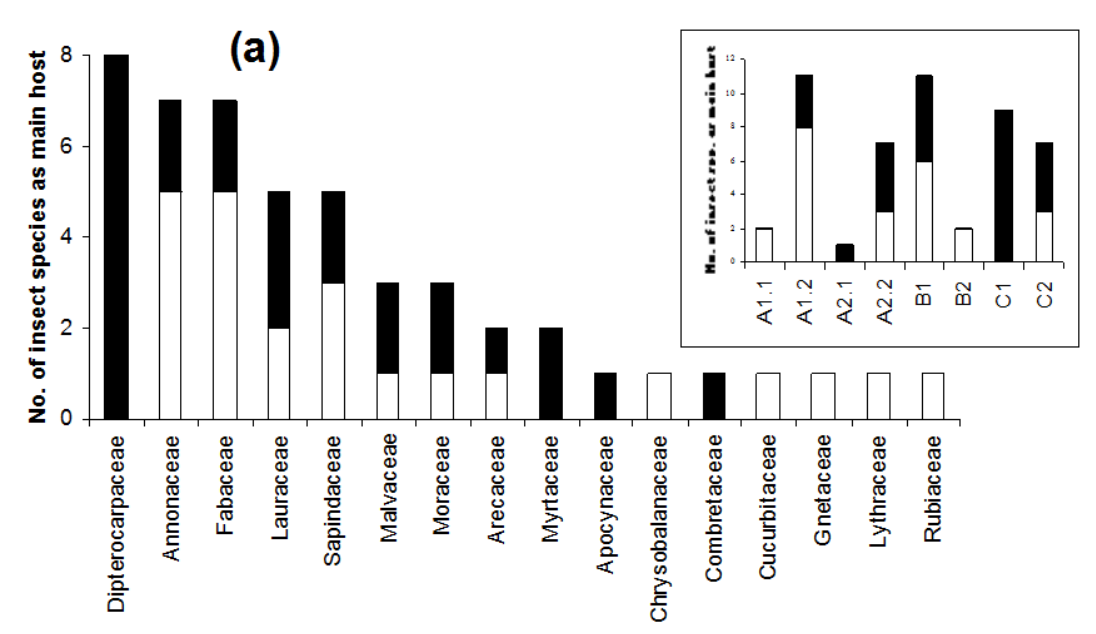

$\left.{ }^{200}\right] \quad$ (b)
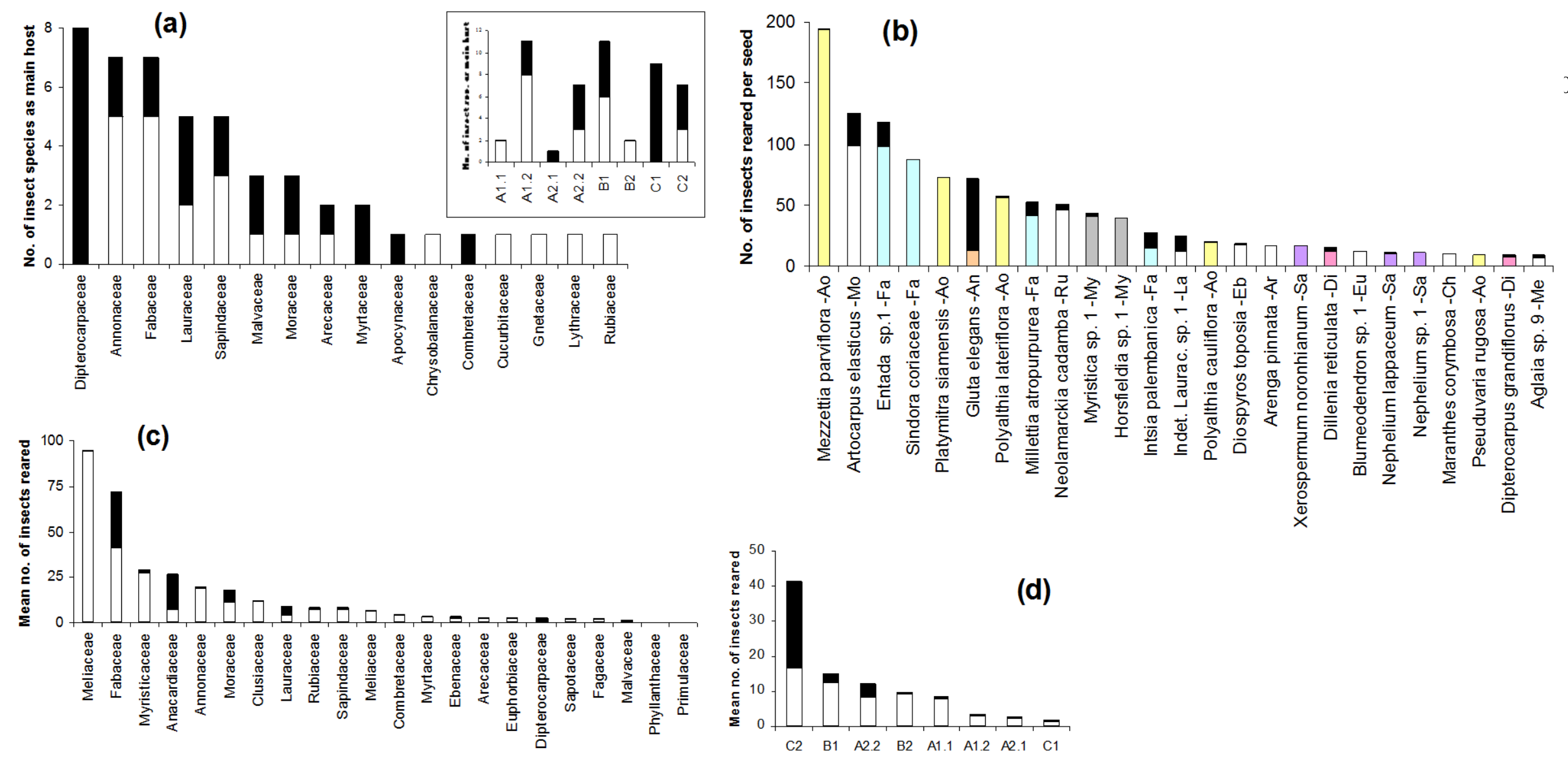

798 Figure 3 Heavily attacked plant species. (a) Number of insect species (white = pulp eaters, black = seed eaters) reared from main hosts (as

799 defined in methods), detailed by plant families. Inset: same presentation, detailed by seed syndrome. (b) Number of insects reared per seed

800 for the 25 most attacked plant species. Black = seed eaters, white or different colour = pulp eaters (same colour denotes same plant family).

801 (c) Average number of insects reared per seed and plant species, detailed by plant family (white $=$ pulp eaters, black $=$ seed eaters). $(\mathrm{d})$

802 Same presentation, detailed by seed syndrome. Abbreviations of families for (b): An=Anacardiaceae; Ao=Annonaceae; Ar=Arecaceae;

$803 \mathrm{Ch}=$ Chrysobalanaceae; Di=Dilleniaceae; Di=Dipterocarpaceae; Eb=Ebenaceae; Eu=Euphorbiaceae; Fa=Fabaceae; La=Lauraceae; 
804 Me=Meliaceae; Mo=Moraceae; My=Myristicaceae; $\mathrm{Ru}=$ Rubiaceae; Sa=Sapindaceae .

805 

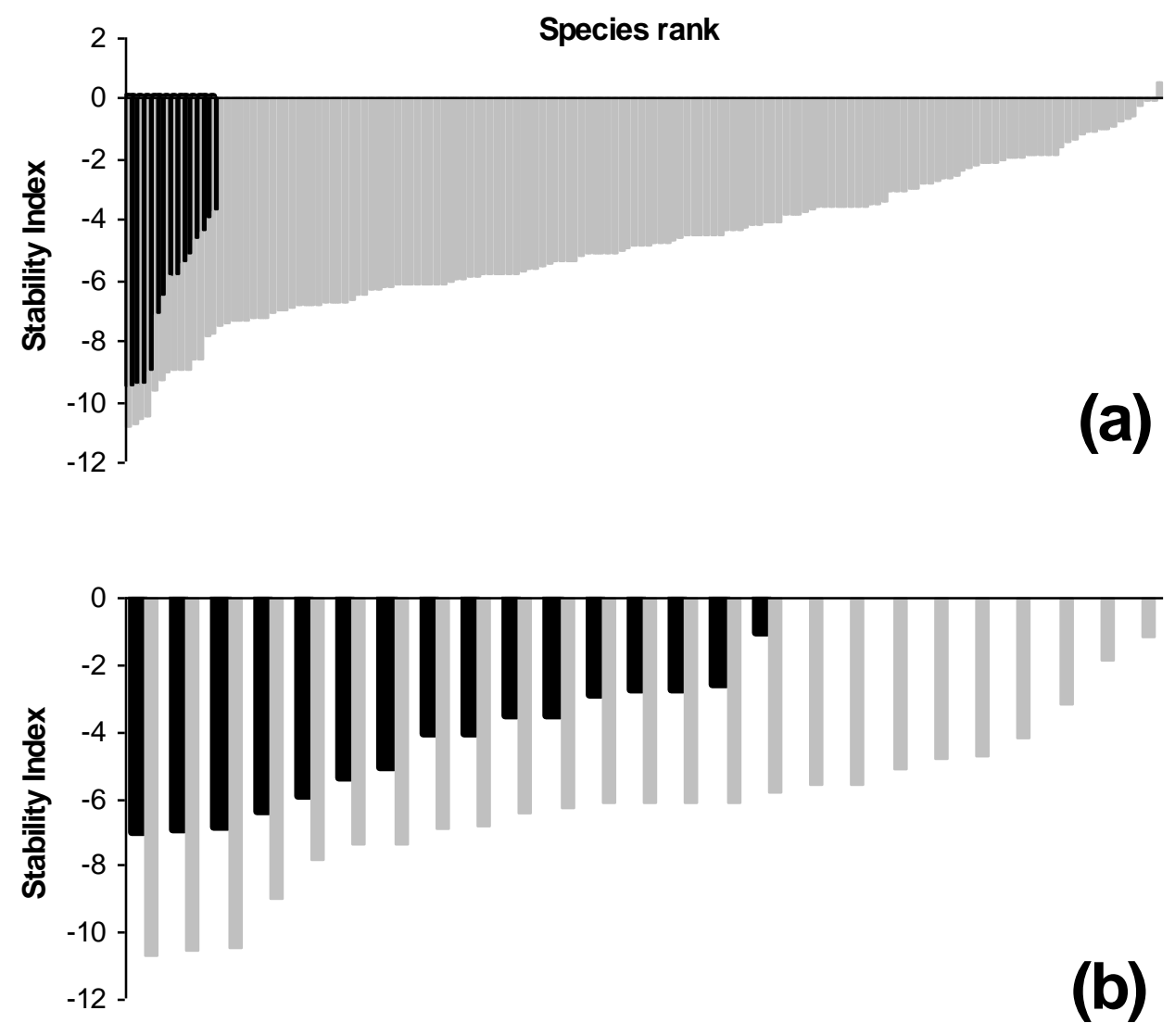

Figure 4 Insect species ranked by their stability index. (a) Species reared from non-dipterocarp hosts (grey bars) vs. species reared from dipterocarp hosts (black bars). (b) Species reared from fleshy fruits (grey bars) vs. dry fruits (black bars). 
Attacked

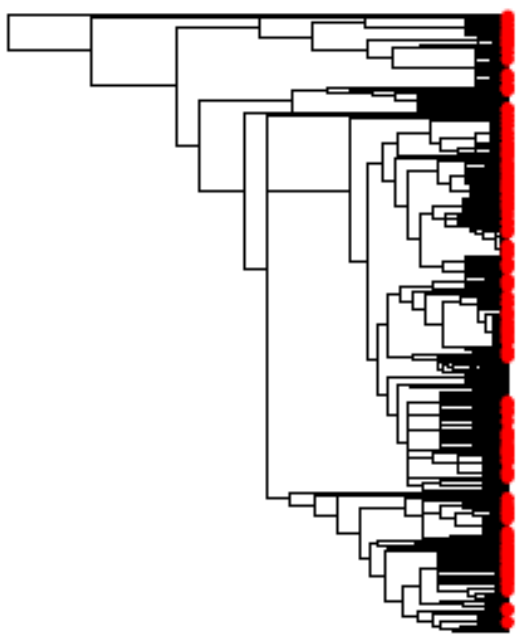

Heavily

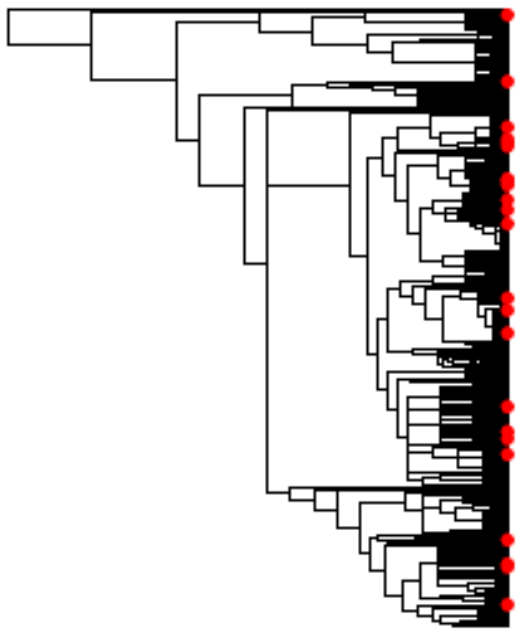

Rarely

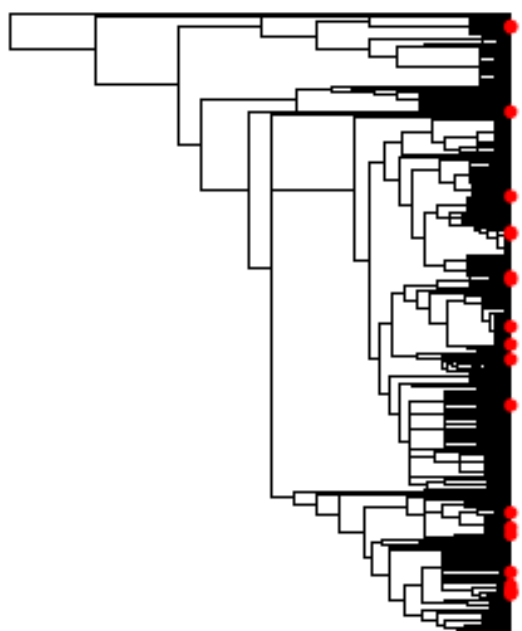

HostsOflcheumonoidea

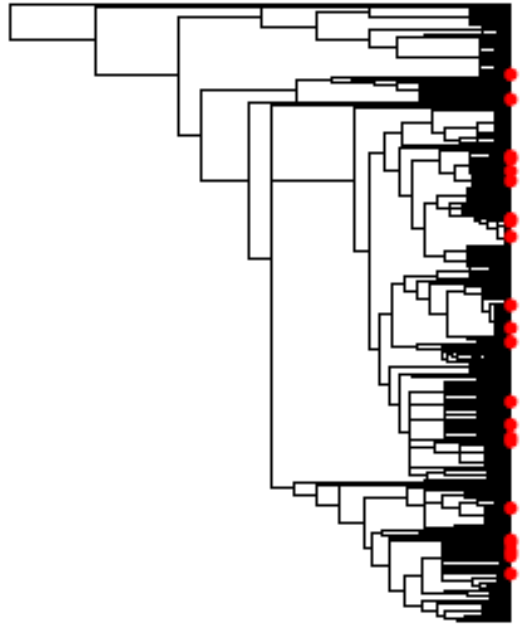

810 Figure 5 Maximum clade credibility consensus trees depicting the phylogenetic 811 relationships between 622 host plant species, with for each consensus tree, taxa marked in 812 red indicate (a) all species attacked, (b) species rarely attacked, (c) species heavily attacked 813 and (d) species from which Ichneumonoidea were reared. 
816 Table 1 Levels of parasitism due to Ichneumonoidea for the main higher insect taxa reared

817 from seeds and fruits at Khao Chong, presented in decreasing \% of species parasited.

818

\begin{tabular}{lcccc}
\hline Taxa & $\begin{array}{c}\text { No. spp. } \\
\text { reared }\end{array}$ & $\begin{array}{c}\text { No. spp. } \\
\text { parasitized }\end{array}$ & $\begin{array}{c}\text { \% species } \\
\text { parasitized }\end{array}$ & $\begin{array}{c}\text { \% individuals } \\
\text { parasitized }\end{array}$ \\
\cline { 1 - 4 } Tephritidae & 26 & 7 & 26.9 & 7.0 \\
Anthribidae & 8 & 1 & 12.5 & 0.3 \\
Curculionidae $*$ & 26 & 3 & 11.5 & 0.8 \\
\cline { 1 - 1 } Tortricidae & 13 & 1 & 7.7 & 4.6 \\
Stratiomyidae & 8 & 0 & 0 & 0 \\
Pyralidae & 8 & 0 & 0 & 0 \\
Crambidae & 15 & 0 & 0 & 0 \\
Scolytinae & 22 & 0 & 0 & 0 \\
& & & & \\
All pulp eaters & 113 & 8 & 7.1 & 6.3 \\
All seed eaters & 34 & 4 & 11.8 & 0.7 \\
All & 147 & 12 & 8.2 & 2.9 \\
\hline
\end{tabular}

* Without Scolytinae

820 